\title{
Effect of Gas Blown Modes on Mixing Phenomena in a Bottom Stirring Ladle with Dual Plugs
}

\author{
Tang HAIYAN, ${ }^{*}$ Guo XIAOCHEN, Wu GUANGHUI and Wang YONG \\ School of Metallurgical and Ecological Engineering, University of Science and Technology Beijing, 30 Xueyuan Road, Haidian \\ District, Beijing, China.
}

(Received on June 11, 2016; accepted on August 26, 2016; J-STAGE Advance published date: October $15,2016)$

\begin{abstract}
Gas stirring plays a significant role in steelmaking process. The stirring effect is often assessed by the mixing time. In the past, the effects of many factors such as the number and position and relative angle of porous plugs in a ladle, as well as gas flowrate on the mixing time have been studied and some beneficial results used in industrial practice. However, for a ladle with dual plugs, the researches on gas flowrate basically focused on the blowing mode with the same gas flowrates for every plug (Mode-S), while the mode with different flowrates (Mode-D) has not yet been reported. In the present work, a water model for a $120 \mathrm{t}$ ladle is carried out to mainly compare the effect of the two gas blowing modes on mixing. Two porous plugs are located at $0.55-0.70 R$ ( $R$ is the radius of ladle bottom), with different relative angles $\left(45-180^{\circ}\right)$ and total flowrates $(6.92-18.45 \mathrm{NL} / \mathrm{min})$. The results show that Mode-D can significantly change the mixing time. Compared with Mode-S, the mixing time is respectively decreased by 50 seconds at $6.92 \mathrm{NL} / \mathrm{min}$ and 30 seconds at $18.45 \mathrm{NL} / \mathrm{min}$ when the plug positions are located at $0.64 \mathrm{R}$. The results of mathematical simulation explain the phenomena. In the Mode-D, the strong gas plume forms a larger circulation flow to stir the ladle and the weak plume forms a smaller one. Under this case, the interference and collision from two plumes are weakened and the dissipation of stirring energy is decreased, thus the mixing time is shortened.
\end{abstract}

KEY WORDS: bottom stirring ladle; gas blown mode; mixing; dual plugs; stirring energy.

\section{Introduction}

Ladle refining plays a significant role in steelmaking process to realize decarburization, desulfurization, deoxidation, inclusion removal and adjusting temperature and composition. The effect of ladle refining has a close relationship with the quality of molten steel and producing efficiency. ${ }^{1-4)}$ Gas stirring is one of the most commonly applied techniques in ladle refining process. Argon gas injection from bottom plugs creates the re-circulatory flow that increases mixing of molten steel and promotes homogenization of chemical constituents and temperature. The argon flow also helps in agglomeration and growth of inclusions. In addition, rising gas bubbles due to argon flow may cause other phenomena such as breaking of slag layer and formation of eye opening at the top. Higher flow increases the eye open area which leads to an increase in the oxidation of steel as well as nitrogen pickup from the atmosphere. Moreover, higher degree of turbulence in this case leads to slag entrapment in steel and enhances the formation of exogenous inclusions. ${ }^{5)}$

Thus, it is of great significance to determine proper argon stirring flowrate. Moreover, for high-capacity ladles used in many steel factories of China, two porous plugs are usually

* Corresponding author: E-mail: tanghaiyan@metall.ustb.edu.cn DOI: http://dx.doi.org/10.2355/isijinternational.ISIJINT-2016-360 utilized, and their positions and relative angle have effect on the homogenization of molten steel. ${ }^{1,6)}$

For the function of argon gas in ladle refining, many studies were performed in the earlier years through water model $^{1,2,4,6)}$ and mathematical simulation ${ }^{5,7-9)}$ from different aspects such as (a) gas injection and transport, ${ }^{10-13)}$ (b) the effect of top slag layer, ${ }^{14-19)}$ (c) stirring and mixing. ${ }^{20-28)}$

In 1975, Nakanishi et al. ${ }^{10)}$ investigated the correlation between gas mixing efficiency and mass transfer in a model ladle and explained this correlation with turbulence theory. Later, Mori and Sano ${ }^{11)}$ summarized an equation to describe the relationship between the bubble size and gas flowrates for a single plug ladle. Sahai and Guthrie developed an effective viscosity model ${ }^{12)}$ and a mean plume velocities model ${ }^{13)}$ having considered gas flowrate and ladle geometry size.

For the effect of top slag layer, some investigations have been performed since 1988. It is well known when the bubbles reach the top slag layer, they will break and the circulation flow will be formed. Mazumdar et al. ${ }^{15)}$ reported the possible roles of upper slag phases and indicated in the model studies that the overlying oil phase dissipated a part of input energy, which lead to the velocity of liquid recirculation and the level of turbulence decreasing significantly. Yasuo et al. $^{16)}$ studied the energy dissipation distribution in gas-stirred ladles without the top layer and showed that only less than $1 \%$ of the energy input from the gas was dis- 
sipated on the surface waves, and energy dissipation rate for the pure liquid zone, plume zone, and spout was 36, 22 and 41 pct., respectively. Mazumdar and Guthrie ${ }^{17)}$ investigated the energy dissipation of ladles with the top layer, indicating that the top layer dissipated about 10 pct. of the input energy, the bubble slippage and wall friction dissipated nearly 70 pct. to 80 pct. Iguchi et al. ${ }^{18)}$ and Han et al. ${ }^{19)}$ investigated the effect of slag viscosity on the ladle mixing and showed that the mixing time increased with increasing slag viscosities. As a result, top layer should be considered for accurate calculation and modelling.

For stirring and mixing, the mixing time of molten steel is usually used as an important criterion to evaluate mixing effect and gas-blowing performance. Nakanishi et al. ${ }^{20)}$ first plotted mixing time data against global rates of specific energy dissipation to predict the mixing time in 1975. Later, they ${ }^{21}$ found the relationship of mixing time and stirring energy. Based on this, other researchers ${ }^{22-24)}$ predicted the mixing time having considered the size of vessel and the height of bath. These studies above mentioned mainly focused on the ladle with single plug.

For the investigated method, Murthy et al. ${ }^{27)}$ proposed that the mixing time neither depended on the locations and sizes of used conductivity probe, nor the positions and the amounts of tracer injected. The result was confirmed by Murthy and Elliott. ${ }^{28)}$ However, Zhu et al. ${ }^{26)}$ expounded the different view of which the mixing time was greatly influenced by tracer adding position based on their experiments. As a result, different researchers possess various views, which may be caused by the differences of ladle size and plug arrangement as well as gas flowrate.

In recent years, ladles with two or more plugs have attracted great attention. Chen et al. ${ }^{29)}$ studied the effects of plug arrangements on the mixing time in 2007 and found that the shortest mixing time could be obtained when the two plugs were symmetrically arranged at half radii in the ladle bottom with a 45 degree of relative angle, however, they did not consider the effect of the plug angles on slag eyes. In 2011, Y. S. Chen et al. ${ }^{9)}$ studied the effect of the number and positions of plugs on mixing time, suggesting that the shortest mixing time could be obtained when the plug at $0.7 \mathrm{R}$ from the center of ladle bottom with only one plug, whereas at $0.5-0.7 \mathrm{R}$ with $60-90$ degree when two plugs. In a recent study, Amaro-Villeda et al. ${ }^{14)}$ found the shortest mixing time was at the position $0.5 \mathrm{R}$ with only one plug, compared with all other cases including two plugs.

From these researches above mentioned, it can be seen that the plug position, relative angle as well as gas flowrate influence the mixing in a ladle. Thus, the studies of the proper arrangement of plugs and the distribution of gas flowrates are of significance to get a better mixing and performance in a ladle refining. Mixing and influencing factors are not the same among different researchers, indicating obtained relative formulas are not universal for all ladles. Moreover, for double plugs, these researches all focused on the same flowrates for every plug, while very few studies were reported on the mixing and flowing under different gas flowrates.

In high-capacity ladles, two plugs are usually employed to shorten the mixing time, basically with the same gas flowrates for every plug. This conventional gas blowing mode (short for Mode-S) exhibits several unfavorable behaviors based on practical operations which can be mainly summarized as: the gas plumes collide and interact with each other in the molten bath, during which stirring energy can be dissipated and consumed. This means that a part of stirring energy is wasted and the stirring efficiency is decreased. Meanwhile, because of the swing and collision of the two plumes, the top slag might be entrapped into the molten steel.

So, another gas blowing mode with different flowrates for every plug (short for Mode-D) is put forward in the present work to solve these problems. In this blowing mode, the weak gas flow is used to stir the stagnant zone at the bottom of the ladle, and the strong one is used to stir the whole ladle by forming a big circulation flow. Thus, the dissipation of the stirring energy will be decreased.

The effects of the two gas blowing modes including the same and different flowrates for every plug on the mixing are compared by hydraulic modeling for a 120 tons ladle in a steel factory of China, intending to obtain low cost and high effective argon stirring case and mode. The empirical expressions between mixing time and other factors are obtained to predict the mixing time.

\section{Experimental Work}

\subsection{Water Modelling}

\subsubsection{Experimental Principle}

An industrial size of metallurgical ladle of 120 tons was used as prototype to design the experimental water model. The scale factor is $1: 3$, and the main parameters of prototype and model ladle are shown in Table 1.

According to the principle of similarity, the power of liquid flowing mainly originates from the buoyancy of bubble for the bottom gas stirring ladle. So, modified Froude numbers $\left(\mathrm{Fr}^{\prime}\right)$ must be equal besides geometric similarity for model and prototype. Modified $\mathrm{Fr}^{\prime}$ is defined as:

$$
\operatorname{Fr}^{\prime}=\frac{\rho_{\mathrm{g}} u^{2}}{\rho_{\mathrm{l}} g H}
$$

Gas flow velocity can be represented as a function of gas flowrate:

$$
u=\frac{4 Q}{\left(\pi \mathrm{d}^{2}\right)}
$$

The Eq. (3) is obtained according to the equation $\left(\mathrm{Fr}^{\prime}\right)_{\mathrm{m}}=$ $\left(\mathrm{Fr}^{\prime}\right)_{\mathrm{p}}$

$$
Q_{\mathrm{m}}=\left[\frac{\rho_{\mathrm{g}, \mathrm{p}}}{\rho_{\mathrm{g}, \mathrm{m}}} \cdot \frac{\rho_{\mathrm{l}, \mathrm{m}}}{\rho_{\mathrm{l}, \mathrm{p}}}\left(\frac{d_{\mathrm{m}}}{d_{\mathrm{p}}}\right)^{4}\left(\frac{H_{\mathrm{m}}}{H_{\mathrm{p}}}\right)\right]^{\frac{1}{2}} Q_{\mathrm{p}} \cdots
$$

Where script $\mathrm{m}$ and $\mathrm{p}$ represent model and prototype,

Table 1. Main parameters of prototype and model ladles.

\begin{tabular}{ccc}
\hline Parameters & Prototype & Model \\
\hline Top diameter, mm & 2889 & 963 \\
Bottom diameter, mm & 2759 & 920 \\
Bath depth, $\mathrm{mm}$ & 2800 & 933 \\
Top diameter of porous brick, $\mathrm{mm}$ & 150 & 50 \\
Liquid density, $\mathrm{kg} / \mathrm{m}^{3}$ & 7000 & 1000 \\
\hline
\end{tabular}


respectively. $\rho_{\mathrm{g}}$ and $\rho_{\mathrm{l}}$ denote the densities of gas and liquid, respectively. $H$ is the depth of molten bath, $d$ is the diameter of plug and $Q$ is the gas flowrate.

Nitrogen was used to simulate argon in the experiment, while the commercial rotormeter in use is calibrated by air, thus, it needs to be corrected according to Eq. (4).

$$
Q_{\mathrm{a}}=Q_{\mathrm{m}} \sqrt{\frac{\rho_{\mathrm{N}_{2}}}{\rho_{\text {air }}}}
$$

where $Q_{\mathrm{a}}$ is the rotormeter reading of the model, $\rho_{\mathrm{N}_{2}}$ and $\rho_{\text {air }}$ are the densities of nitrogen gas and air, respectively.

Substituting Eq. (3) into Eq. (4), the following relationship is obtained:

$$
Q_{\mathrm{a}}=0.023063 Q_{\mathrm{p}}
$$

According to Eq. (5), the gas flowrate of the rotormeter can be obtained by the given prototype flowtate.

\subsubsection{Experimental Setup and Method}

The experimental apparatus is shown in Fig. 1.

The mixing in the ladle under different gas blown modes was studied by conductivity method. The conductivity electrode was first calibrated before the experiment. During experiment, nitrogen gas was injected into the bath through plugs located at the different positions, and one electrode was put into "active zone" near the liquid level, the other was put into "stagnant zone" near the bath bottom and saturated $\mathrm{KCl}$ solution as tracer was added into the bath surface from the position of alloy wire fed in actual production. The output signal of electrical conductivity meter was recorded by a personal computer combined with DJ800 multifunctional monitoring system.

In previous studies, ${ }^{6,15,18,22,30)}$ only one electrode was put into certain position of a ladle. However, the electrical conductivity value might vary when the electrode was put at different positions. To avoid the effect, two electrodes were put in the different positions to collect the residence time distribution (RTD) curves during $240 \mathrm{~s}$ in the present study, making sure the ladle mixed. The mixing time $\tau_{\mathrm{m}}$ is defined as the longer time beyond which the changes of the relative electrical conductivities of two electrodes are less than $5 \%$ of the steady state after addition of tracer as Fig. 2. The relative electrical conductivity of every electrode refers to the difference between after and before the tracer added. Every experiment was repeated three times and the mean value was taken as mixing time.

In our pre-experiment for this ladle, tracers were added

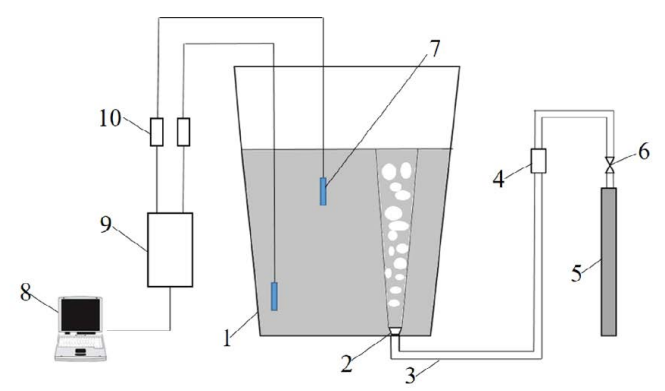

1. ladle 2. porous plug 3. vent pipe 4. rotormeter 5. nitrogen tank 6. relief pressure valve 7. electrode 8. computer 9. DJ800 multifunctional monitoring system 10. conductivity meter

Fig. 1. Experimental apparatus of water model. (Online version in color.) from different positions of the ladle top at a certain plug position and relative angle, the mixing time was measured with the method above mentioned, and the results showed that the position of tracers had little effect on the mixing time. Therefore, the position of tracers in the following experiments is fitted at that of alloy wire fed in actual production.

Table 2 describes the variables included in the experimental work. The experiments were divided into two parts, in which one part was the Mode-S scheme and the other was the Mode-D scheme. The gas total flowrates of 6.92 , 11.53 , and $18.45 \mathrm{NL} / \mathrm{min}$ were equally distributed to two porous plugs in the former, while they were divided into a weak $(2.3 \mathrm{NL} / \mathrm{min})$ and a strong flowrate $(4.62,9.23,16.15$ $\mathrm{NL} / \mathrm{min}$ ) in the latter.

The arrangement of porous plugs is shown in Fig. 3, in which T1, T4, T7, T10 were designed at $0.55 \mathrm{R}(\mathrm{R}$ is the radius of the ladle) from the center of the ladle, T2, T5, T8 and T11 were at $0.64 \mathrm{R}$, and T3, T6, T9, T12 at 0.7R. They were combined at the different relative angles such as $45^{\circ}$, $90^{\circ}, 135^{\circ}$ and $180^{\circ}$ (it refers to the angle formed by two

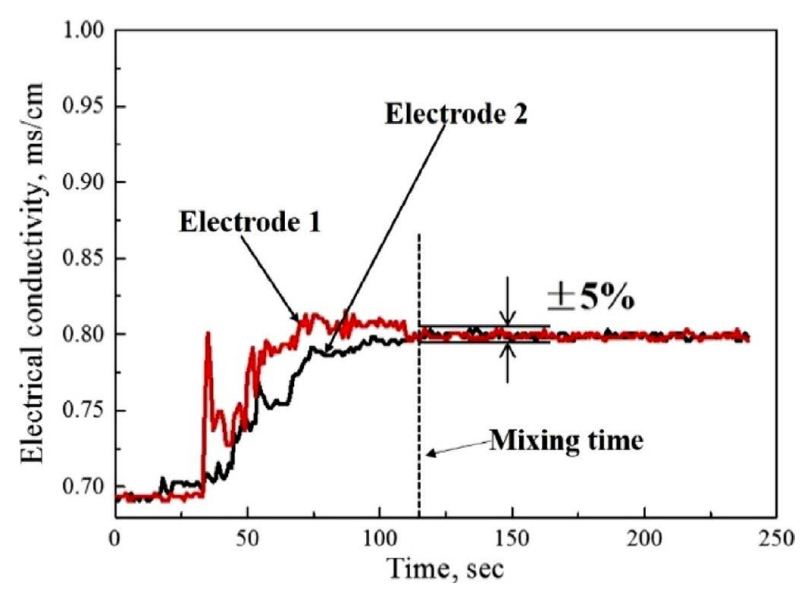

Fig. 2. Mixing time schematic. (Online version in color.)

Table 2. Variables included in the experimental work.

\begin{tabular}{ccc}
\hline Parameters & Prototype & Water Model \\
\hline Plug radial positions & $0.64 \mathrm{R}$ & $0.55 \mathrm{R}, 0.64 \mathrm{R}, 0.70 \mathrm{R}$ \\
Angles, $^{\circ}$ & 90 & $45,90,135,180$ \\
Flowrates, NL/min $^{\circ}$ & 100 to 800 & 2.3 to 18.45 \\
\hline
\end{tabular}

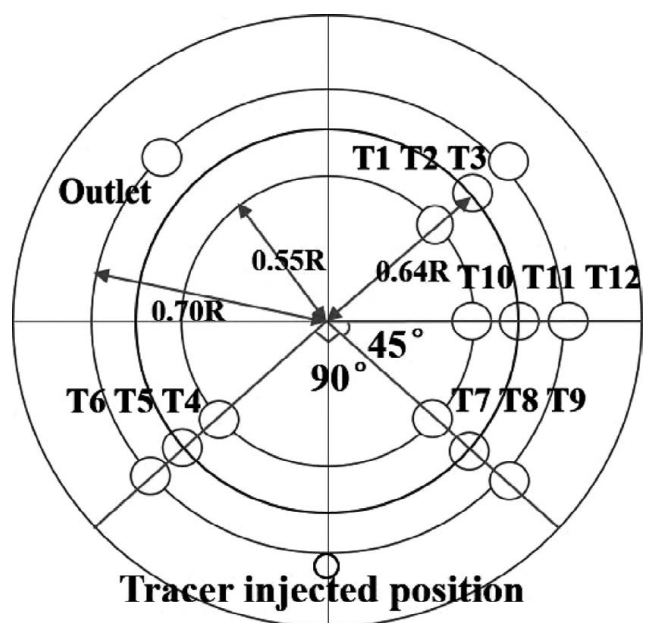

Fig. 3. The arrangements of porous plugs at ladle bottom. 
plugs with the center of the ladle bottom). The porous plugs of prototype ladle are at $\mathrm{T} 5$ and $\mathrm{T} 8$.

\subsection{Mathematical Modeling}

\subsubsection{Control Equation}

The multiphase flow in a gas-stirred ladle was simulated by the volume of fluid (VOF) model, and the control equations were described as follows: ${ }^{5,8,31-34)}$

(1) Continuity equation

$$
\frac{\partial \rho}{\partial t}+\frac{\partial\left(\rho u_{i}\right)}{\partial x_{i}}=0
$$

(2) Momentum equation

$$
\begin{aligned}
\frac{\partial\left(\rho u_{i}\right)}{\partial t}+\frac{\partial\left(\rho u_{i} u_{j}\right)}{\partial x_{i}} & =-\frac{\partial p}{\partial x_{i}}+\frac{\partial}{\partial x_{i}}\left[\mu_{e}\left(\frac{\partial u_{i}}{\partial x_{j}}+\frac{\partial u_{j}}{\partial x_{i}}\right)\right] \ldots \\
& +\rho g_{i}+f_{\sigma}+F_{b, i}
\end{aligned}
$$

Where $\rho$ is the density, $u_{i}$ is the fluid velocity, and $\mu_{e}$ is the effective viscosity, $p$ is the pressure, $g_{i}$ is the gravitational accelerate.

(3) Turbulent equations:

The standard $k-\varepsilon$ equation is used to model turbulence, which solves two equations for the transport of turbulent kinetic energy and its dissipation rate to obtain the effective viscosity field.

$$
\begin{aligned}
\frac{\partial(\rho k)}{\partial t}+\frac{\partial\left(\rho k u_{i}\right)}{\partial x_{i}} & =\frac{\partial}{\partial x_{i}}\left[\left(\mu+\frac{\mu_{\mathrm{t}}}{\sigma_{\mathrm{k}}}\right) \frac{\partial k}{\partial x_{i}}\right]+G_{\mathrm{k}}-\rho \varepsilon \ldots \\
\frac{\partial(\rho \varepsilon)}{\partial t}+\frac{\partial\left(\rho \varepsilon u_{i}\right)}{\partial x_{i}}= & \frac{\partial}{\partial x_{i}}\left[\left(\mu+\frac{\mu_{\mathrm{t}}}{\sigma_{\varepsilon}}\right) \frac{\partial \varepsilon}{\partial x_{i}}\right] \\
& +C_{1 \varepsilon} \frac{\varepsilon}{k}\left(G_{\mathrm{k}}+C_{3 \varepsilon} G_{\mathrm{b}}\right)-C_{2 \varepsilon} \rho\left(\frac{\varepsilon^{2}}{k}\right) \ldots
\end{aligned}
$$

Where $k$ is the turbulence kinetic energy, $\varepsilon$ is the turbulent kinetic energy dissipation rate, $x_{i}$ represents the spatial coordinates for different directions. $G_{\mathrm{k}}$ is the turbulent kinetic energy source term caused by mean velocity gradient, $G_{\mathrm{b}}$ is the turbulent kinetic energy source term caused by buoyancy. These terms are calculated by Eqs. (10) and (11), respectively.

$$
\begin{gathered}
G_{\mathrm{k}}=-\rho u_{i} u_{j} \frac{\partial u_{i}}{\partial x_{i}} \ldots \ldots . . \\
G_{\mathrm{b}}=-g_{i}\left(\mu_{\mathrm{t}} / \rho P r_{t}\right) \frac{\partial \rho}{\partial x_{i}} \\
\mu_{\mathrm{t}}=\rho C_{\mu}\left(\frac{k^{2}}{\varepsilon}\right) \ldots \ldots . . .
\end{gathered}
$$

The turbulent viscosity is calculated by Eq. (12) using the $k$ and $\varepsilon$ from Eqs. (8) and (9) respectively. In these equations, constants are taken as follows: $C_{1 \varepsilon}=1.44, C_{2 \varepsilon}=1.92$, $C_{3 \varepsilon}=1.0, C_{\mu}=1.44, \sigma_{\varepsilon}=1.3 .^{5,8,31)}$

(4) Volume of Fluid (VOF) model

Fluid volume equation: ${ }^{33)}$

$$
\frac{1}{\rho_{\mathrm{q}}}\left[\frac{\partial}{\partial t}\left(\alpha_{\mathrm{q}} \rho_{\mathrm{q}}\right)+\nabla \cdot\left(\alpha_{\mathrm{q}} \rho_{\mathrm{q}} \overrightarrow{\mathrm{q}}_{\mathrm{q}}\right)\right]=S_{\alpha_{\mathrm{q}}}+\sum_{\mathrm{p}=1}^{n}\left(\dot{m}_{\mathrm{pq}}-\dot{m}_{\mathrm{qp}}\right) \ldots
$$
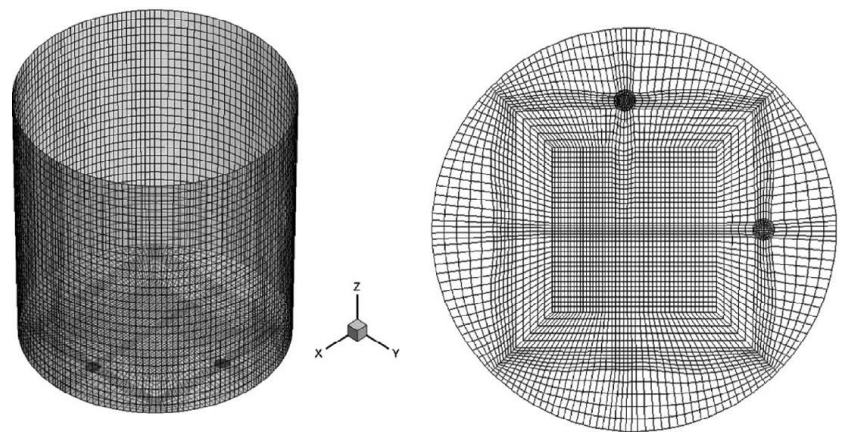

Fig. 4. Mesh structures of the ladle and its bottom surface.

Where $\dot{m}_{\mathrm{pq}}, \dot{m}_{\mathrm{qp}}$ represent the mass transfer from phase $\mathrm{p}$ to $\mathrm{q}$ and phase $\mathrm{q}$ to $\mathrm{p}$ in unit time and volume, respectively; $\alpha_{\mathrm{q}}$ is the volume fraction of phase $\mathrm{q}, \rho_{\mathrm{q}}$ is the density of phase q, $S_{\alpha_{q}}$ is the source term taken as 0 in Fluent.

The volume fraction of main phase is not calculated in Fluent, while it can be acquired by the Eq. (14). This equation represents the volume fraction of each phase in the sum of 1 in fluid.

$$
\sum_{\mathrm{q}=1}^{\mathrm{n}} \alpha_{\mathrm{q}}=1
$$

\subsubsection{Boundary Conditions and Solution Method}

To provide the guide for industrial practice, the prototype ladle with $150 \mathrm{~mm}$ thick of slag layer was calculated, and its size is in Table 1. Velocity inlet boundary condition was used at the inlet of the ladle, and its value determined by the gas flowrate and area. Pressure outlet boundary condition was taken at the outlet of the ladle bottom. The ladle walls were taken to be no-slip boundary, and near wall using a standard wall function.

The computational fluid dynamics ANSYS Fluent CFD software, ${ }^{35)}$ was employed to perform the calculation. The mesh for the computational domain, as in Fig. 4, was divided into a non-uniform grid of $\sim 150000$ cells. PISO (Pressure Implicit with Splitting of Operator) transient algorithm was adopted with $0.001 \mathrm{~s}$ of every time step. Convergence was defined when the unscaled absolute residuals in all equations was reduced to below $1 \times 10^{-5}$. After reaching stationary flow with this method, data were collected.

\section{Results and Discussion}

\subsection{The Same Flowrates for Two Plugs (Mode-S)}

\subsubsection{Effect of Plug Positions:}

In the previous studies, there were two different views about the effect of plug positions on mixing time. Some investigators $\left.{ }^{6}\right)$ reported the mixing time varied drastically when the plug moved from $0.5 \mathrm{R}$ to the wall, but the tendency was different at various angles. However, the results of Terrazas et al. ${ }^{30)}$ showed that mixing time did not experience major changes when the plug position moved close to the wall. Figure 5 is our results, which reflects the effect of plug positions on mixing time as a function of gas total flowrate and the relative angles. In these cases, the gas total flowrate is equally distributed to two plugs.

It is seen that the mixing time all increases from $0.55 \mathrm{R}$ to $0.64 \mathrm{R}$, then decreases from $0.64 \mathrm{R}$ to $0.7 \mathrm{R}$ at three total 

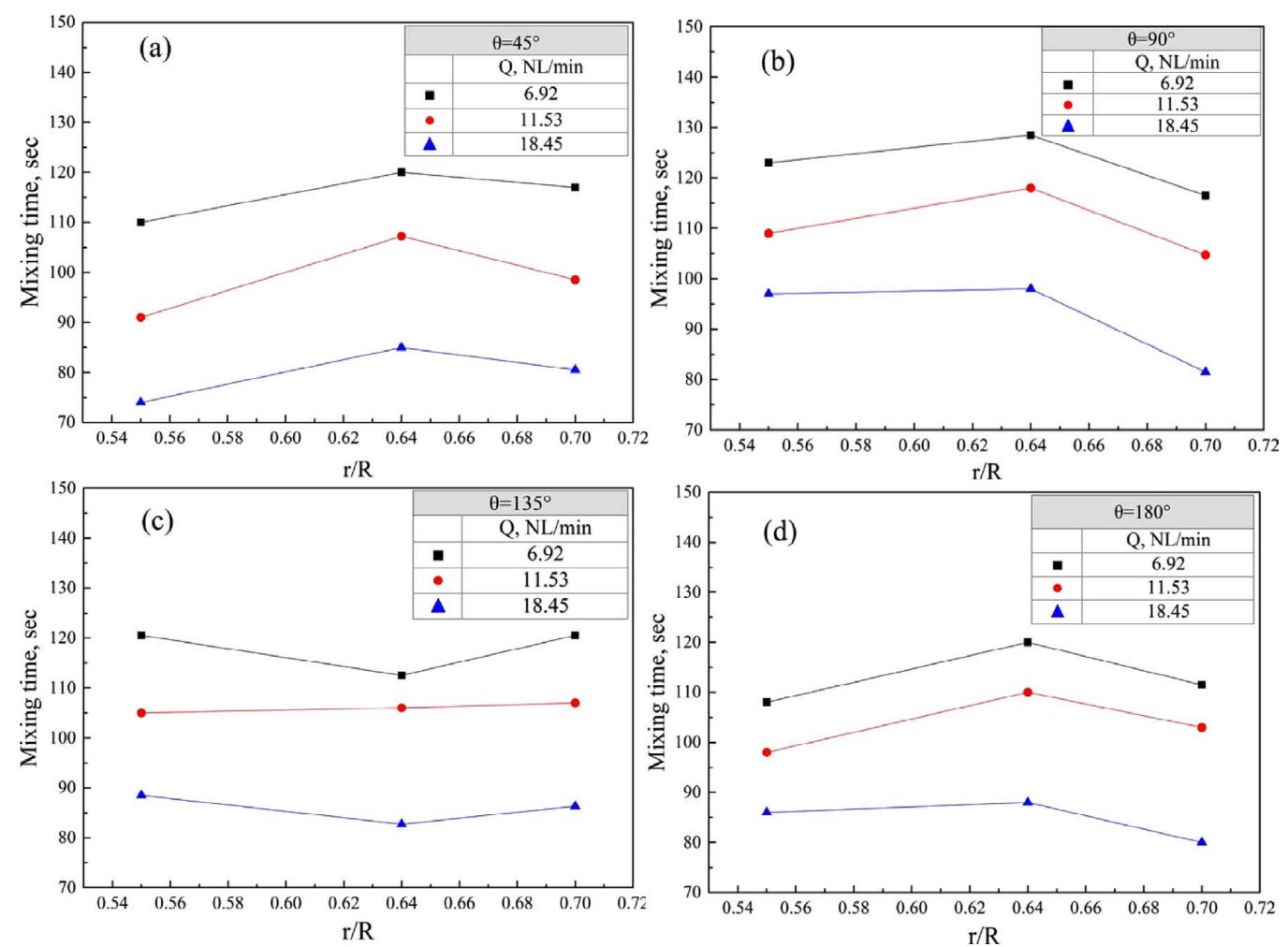

Fig. 5. Effect of plug positions on mixing time for the different relative angles at three gas total flowrates. (Online version in color.)

flowrates except the case with $135^{\circ}$ of relative angle (Fig. $5(\mathrm{c})$ ), but the change is small with $15 \%$ at most. By comparison, the mixing time at $45^{\circ}$ and $0.55 \mathrm{R}$ is the shortest with $73 \mathrm{~s}$ at $18.45 \mathrm{NL} / \mathrm{min}$ of stirring condition and $110 \mathrm{~s}$ at $6.92 \mathrm{NL} / \mathrm{min}$ of stirring condition, respectively. The optimized position and angle are consistent with the Ref. 29).

The reasons can be explained as follows: for the ladle of dual plugs, when the gas is injected into the ladle, two circulation flows will be formed at the sides of every plume, one is between the plume and ladle wall, the other is between plumes. The circulation flows between plumes will interfere and collision, consuming a part of stirring energy. The wall also absorbs part stirring energy. The mixing effect of the ladle mainly depends on the stirring by these circulation flows. The closer the plug is away from the ladle center and the smaller the relative angle is, the larger the circulation flow between the plume and ladle wall is, further the better mixing effect. Therefore, the mixing time is shorter at $0.55 \mathrm{R}$ than at $0.64 \mathrm{R}$. Whereas at $0.7 \mathrm{R}$, the circulation flow between the plume and the wall impairs, and a part of stirring energy is consumed by the wall. However, the energy dissipation from gas collision and interference between plumes are also weakened correspondingly due to farther distance between plugs. Thus, the general mixing time is also shorter than $0.64 \mathrm{R}$.

These positions from $0.7 \mathrm{R}$ to the wall have not been used in our experiments, considering the erosion and washing for refractory walls in these positions.

\subsubsection{Effect of the Angles between Plugs:}

Figures 6(a)-6(c) shows the effect of angles between plugs and positions on mixing time at different total flowrates. It can be seen that the fluid flow becomes complex in the presence of multiple variables. Generally, the mixing time increases when the angle between plugs changes from $45^{\circ}$ to $90^{\circ}$. However, the slope becomes small from $0.55 \mathrm{R}$ to $0.7 \mathrm{R}$. When at $0.55 \mathrm{R}$, the average slope is 0.29 , and it becomes 0.22 and 0.05 respectively at $0.64 \mathrm{R}$ and $0.7 \mathrm{R}$. This means the farther the plug is away from the ladle center, the weaker the effect of angles is. When the angle varies from $90^{\circ}$ to $180^{\circ}$, the mixing time generally decreases due to the stirring energy consumed by the collision and interaction of two plumes drops with the increasing angles.

Comparing Figs. 6(a)-6(c), the case $0.55 \mathrm{R}$ and $45^{\circ}$ can obtain the shortest mixing time. However, from the industrially practical view, the slag eye will enlarge at relative angle $45^{\circ}$ and reoxidation opportunity increases. Figure 7 shows the exposed slag eyes at different relative angles when the gas total flowrate is $11.53 \mathrm{NL} / \mathrm{min}$, in which the slag eye of Fig. 7(a) is mixed in a large one due to the two plumes too close. Thus, the case is not suggested to use in practice. Besides, these cases $0.7 \mathrm{R}+180^{\circ}, 0.64 \mathrm{R}+135^{\circ}$, and $0.55 \mathrm{R}+180^{\circ}$ can also acquire shorter mixing time than the prototype case $0.64 \mathrm{R}+90^{\circ}$, which is suggested as the optimized cases in industrial operation.

\subsubsection{Effect of Gas Flowrates:}

Figure 8 shows the effect of gas total flowrates on mixing time at plug position $0.7 \mathrm{R}$ and different relative angles, Fig. 9 displays that at $180^{\circ}$ and different positions. It is seen that the mixing time significantly decreases with increasing flowrate, and its influence is larger than the relative angles and positions because the mixing of the ladle is mainly decided by the stirring energy, whereas the stirring energy has close relationship with the flowrate. ${ }^{18)}$ The references showed that the mixing time existed a critical value with the increasing flowrate, i.e., when the flowrate increased to a critical value, the mixing time did not necessarily decrease whereas 

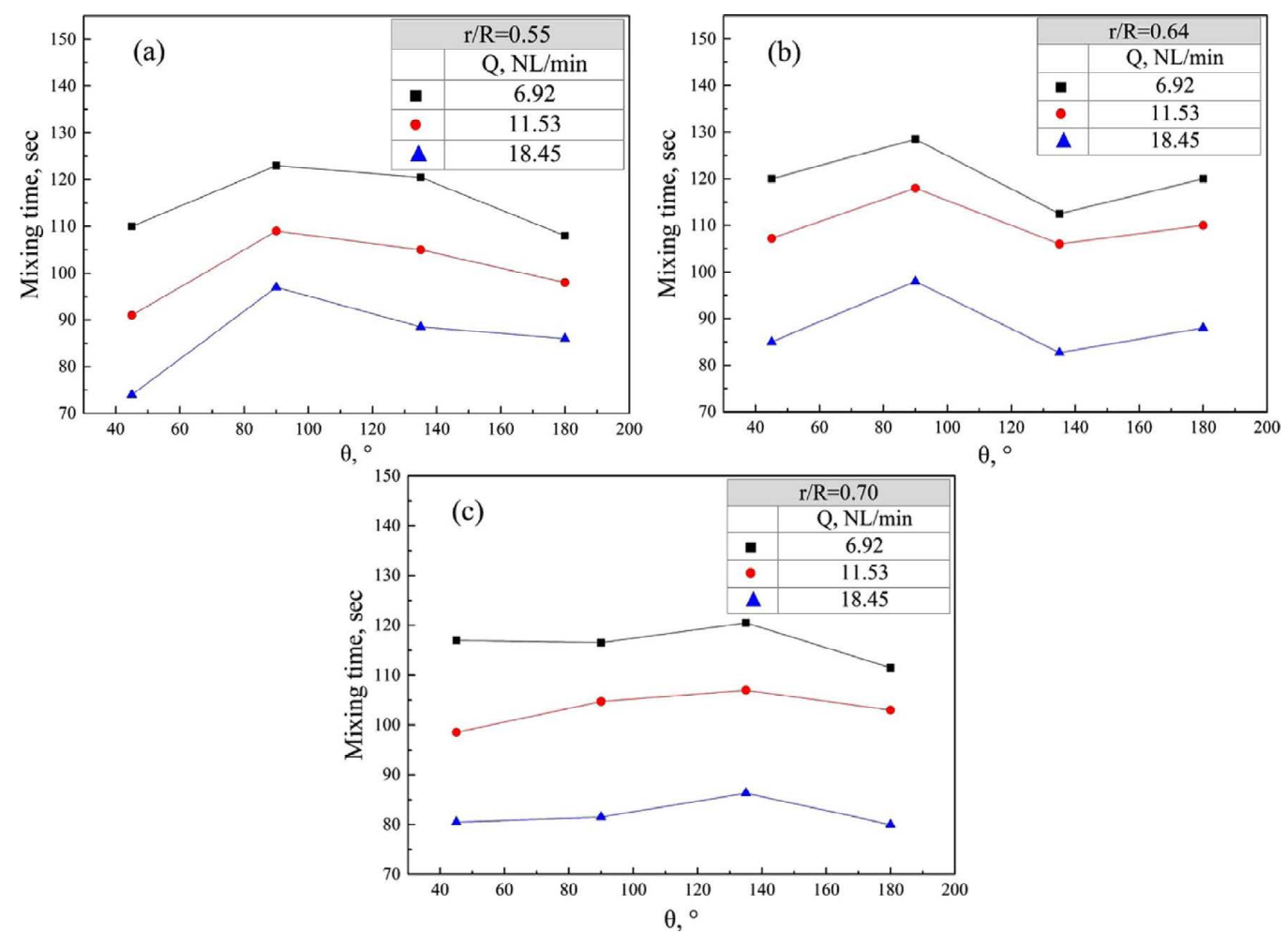

Fig. 6. Effect of the angles between plugs on mixing time for three positions at different gas total flowrates. (Online version in color.)

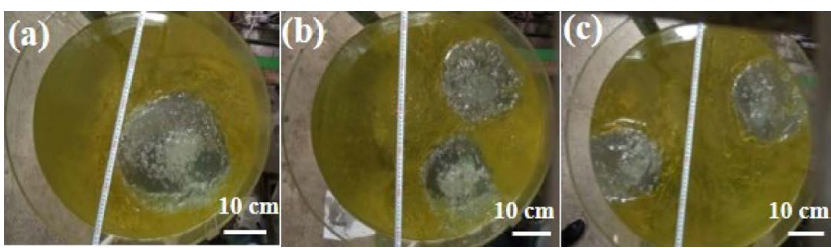

Fig. 7. Top view of slag eyes at gas total flowrate $11.53 \mathrm{NL} / \mathrm{min}$, (a) $45^{\circ}$ (b) $90^{\circ}$ (c) $180^{\circ}$. (Online version in color.)

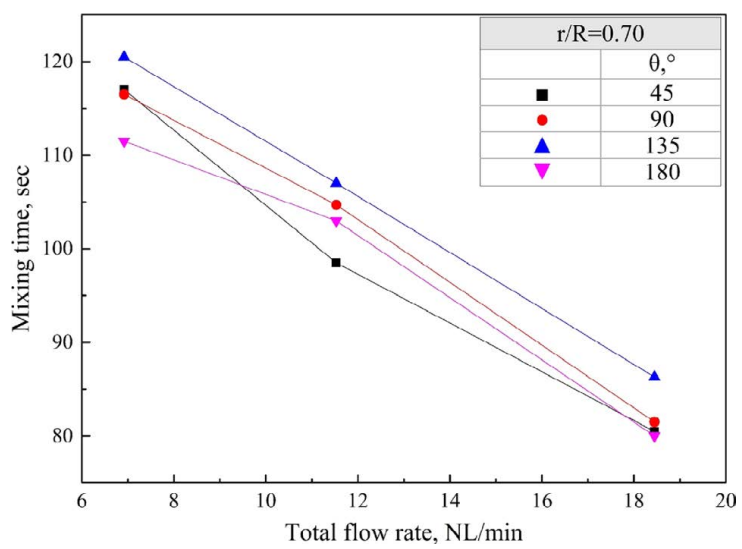

Fig. 8. Effect of gas flowrates on mixing time at plug position $0.70 \mathrm{R}$ and different relative angles. (Online version in color.)

increased $^{1)}$ or almost unchangeable ${ }^{30)}$ due to redundant stirring energy being used to open slag eye and/or dissipate into air rather than stir molten bath. For different ladles, the critical value was variable. However, in the present flowrate range, the mixing time always decreases with the increasing flowrate.

Comprehensively considering the change of mixing time and its value as well as slag eye exposure, the case $0.7 \mathrm{R}$ and $180^{\circ}$ seems better with the mixing time decreasing from

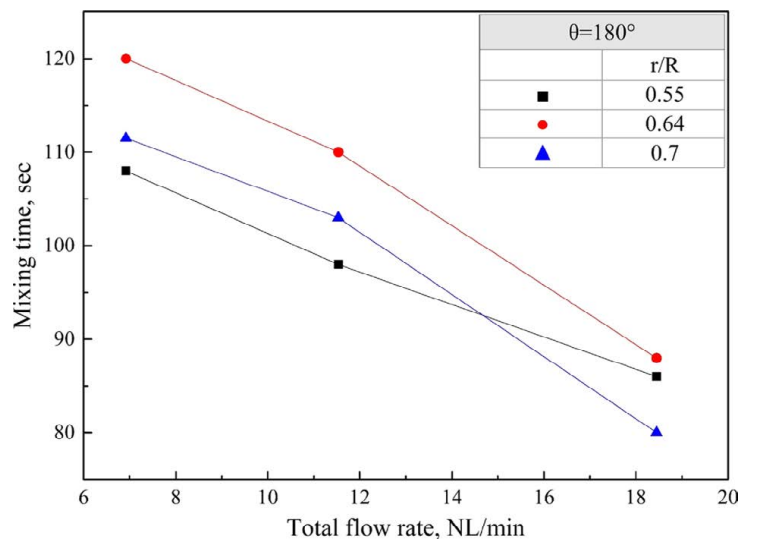

Fig. 9. Effect of gas flowrates on mixing time at $180^{\circ}$ and different plug positions. (Online version in color.)

$111 \mathrm{~s}$ at the total flowrate $6.92 \mathrm{NL} / \mathrm{min}$ to $82 \mathrm{~s}$ at the total flowrate $18.45 \mathrm{NL} / \mathrm{min}$. Compared with the prototype case, the mixing time is decreased by $18 \mathrm{~s}$ and $16 \mathrm{~s}$ respectively at the corresponding flowrates.

\subsection{The Different Flowrates for Two Plugs (Mode-D)}

To compare the influence of the gas blowing modes on mixing, the cases were designed with two plugs were all located at $0.64 \mathrm{R}$ but different angles $\left(45^{\circ}-180^{\circ}\right)$ and flowrates. The total flowrates $6.92,11.53$ and $18.45 \mathrm{NL} / \mathrm{min}$ are divided into a weak $(2.3 \mathrm{NL} / \mathrm{min})$ and a strong flowrate $(4.62,9.23,16.15 \mathrm{NL} / \mathrm{min})$ for two plugs in the experimental process of Mode-D. The comparison results are shown in Fig. 10. It is seen that the change tendency is consistent for two modes, with which the mixing time first increases from $45^{\circ}$ to $90^{\circ}$, then decreases from $90^{\circ}$ to $135^{\circ}$, and little change from $135^{\circ}$ to $180^{\circ}$. An obvious advantage can be seen for Mode-D. Compared with Mode-S, the mixing time is shortened by about $50 \mathrm{~s}$ under the stirring conditions of 


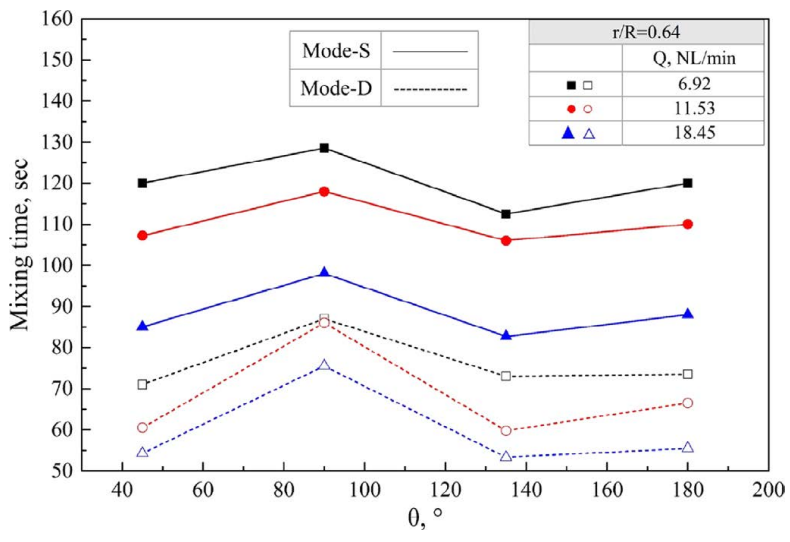

Fig. 10. Comparison of the effect of relative angles on mixing time at the different blowing modes. (Online version in color.)

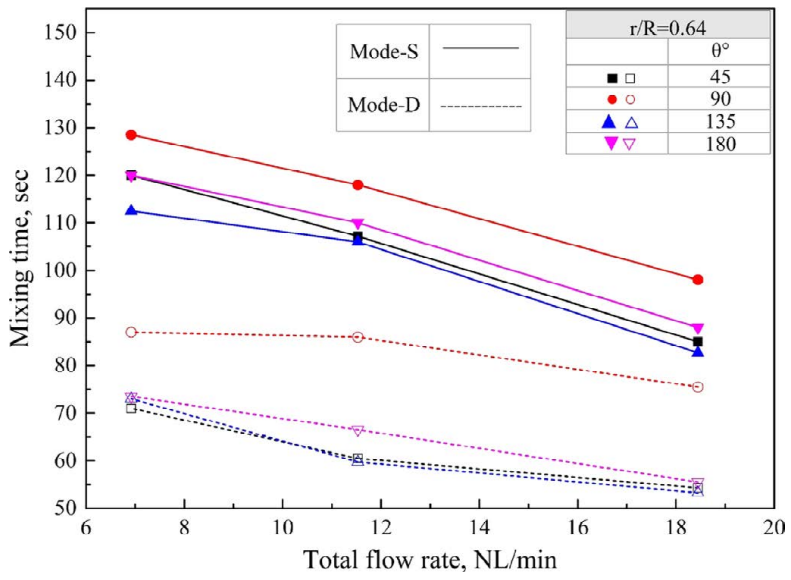

Fig. 11. Comparison of the effect of gas flowrates on mixing time at the different blowing modes. (Online version in color.)

the total flowrate $6.92 \mathrm{NL} / \mathrm{min}$ and $11.53 \mathrm{NL} / \mathrm{min}$, and $30 \mathrm{~s}$ at $18.45 \mathrm{NL} / \mathrm{min}$ of stirring condition. The reason will be explained by mathematical simulation results later.

Figure 11 gives the comparison of the effect of gas total flowrates on mixing time at the different blowing modes. The mixing time all decreases with increasing flowrate, however, the corresponding values with Mode-D are smaller than with Mode-S. The shortest mixing time is $53 \mathrm{~s}$ at $135^{\circ}$ and total flowrate $18.45 \mathrm{NL} / \mathrm{min}$ (in which the weak flowrate is $2.3 \mathrm{NL} / \mathrm{min}$ and the strong flowrate $16.15 \mathrm{NL} / \mathrm{min}$ ), $45 \mathrm{~s}$ shorter than the corresponding value of Mode-S. It is also found that the difference of mixing time is minor between $45^{\circ}, 135^{\circ}$ and $180^{\circ}$ of Mode-D. However, $90^{\circ}$ shows a longer mixing time. The average change of mixing time with increasing flowrate of Mode-D is smaller than Mode-S.

It should be pointed out that in order to compare with the ladle prototype in industrial practice, plug positions of Mode-D were only chosen at $0.64 \mathrm{R}$; the positions of $0.55 \mathrm{R}$ and $0.7 \mathrm{R}$ will be studied in the further work.

\subsection{Results of Mathematical Modeling}

\subsubsection{Validation of CFD Model}

CFD model has been widely used in the simulation of ladles and proved to be fairly reliable., ${ }^{5,-9)}$

Validation of this CFD model were carried out by comparing the present simulation results with the experiment from literature 26) and the simulation from literature 5), (a)

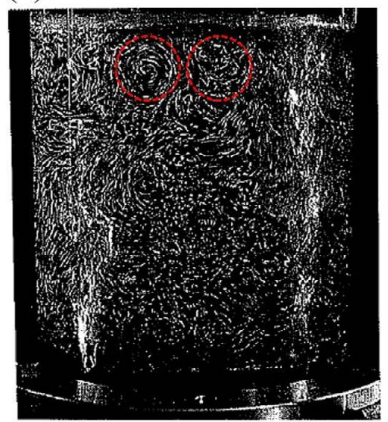

(b)

(c)

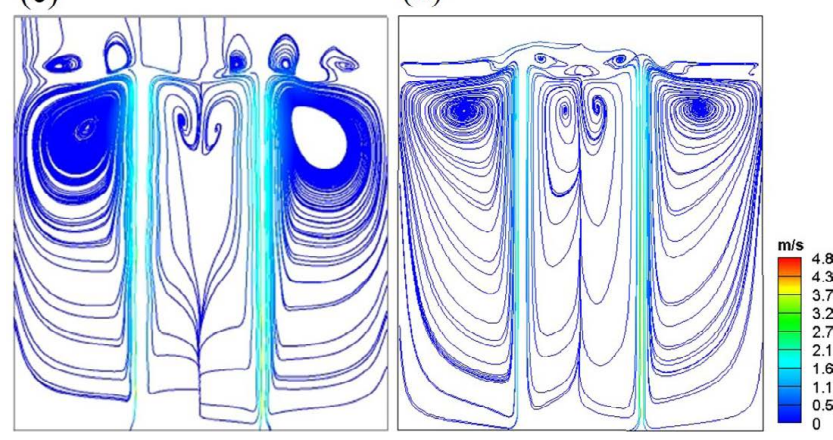

Fig. 12. Validation of CFD model (a) literature 26) result, (b) present simulation result for literature 26), (c) literature 5) result, (d) present simulation result for literature 5). (Online version in color.)

as shown in Fig. 12. Figures 12(a) and 12(c) represent the literature results, while Figs. 12(b) and 12(d) display the simulation results according to our CFD model. As seen, the velocity streamlines are similar to what are found in literatures, which shows that the mathematical model established in the present work is reasonable, it can be used to simulate the subsequent cases.

\subsubsection{Comparison of Two Gas Blowing Modes for the Case $0.64 \mathrm{R}$ with $90^{\circ}$}

To explain the difference between two modes and provide guide for the industrial ladle in use, the flow fields of prototype ladle (plug positions at $0.64 \mathrm{R}$ and relative angle $90^{\circ}$ ) with Mode-S and Mode-D were simulated as an example. The total flowrate was controlled at $800 \mathrm{NL} / \mathrm{min}$ (corresponding to water model $18.45 \mathrm{NL} / \mathrm{min}$ ). The gas flowrate of every plug using Mode-S was $400 \mathrm{NL} / \mathrm{min}$ (corresponding to water model $9.23 \mathrm{NL} / \mathrm{min}$ ). The weak plug flowrate using Mode-D was $100 \mathrm{NL} / \mathrm{min}$ (water model $2.3 \mathrm{NL} / \mathrm{min}$ ), and the strong plug flowrate $700 \mathrm{NL} / \mathrm{min}$ (water model 16.14 $\mathrm{NL} / \mathrm{min}$ ). Figure $\mathbf{1 3}$ is the comparison of velocity vectors between using Mode-S and Mode-D at the main section. The velocity of the central plumes is much higher than the other region, which is similar to the real production. The shape of the two plumes of Mode-S (see Fig. 13(a)) are nearly the same, while it is different for Mode-D (Fig. 13(b)).

Figure 14 compares the velocity streamlines at planes $\mathrm{X}-\mathrm{Z}$ and $\mathrm{Y}-\mathrm{Z}$ for two modes. It is clearly seen that the flow characteristics are different. Using Mode-S (see Figs. 14(a), 14(c)), the flow fields of two plugs is nearly the same with every plume forming two circulation flows, in which one is between plume and wall, and the other is between plumes. The vortex cores between plumes are at the same height, and the streamlines between plumes overlap and collide 
(a) $\mathrm{Q}=\mathbf{4 0 0}+\mathbf{4 0 0} \mathrm{NL} / \mathrm{min}$

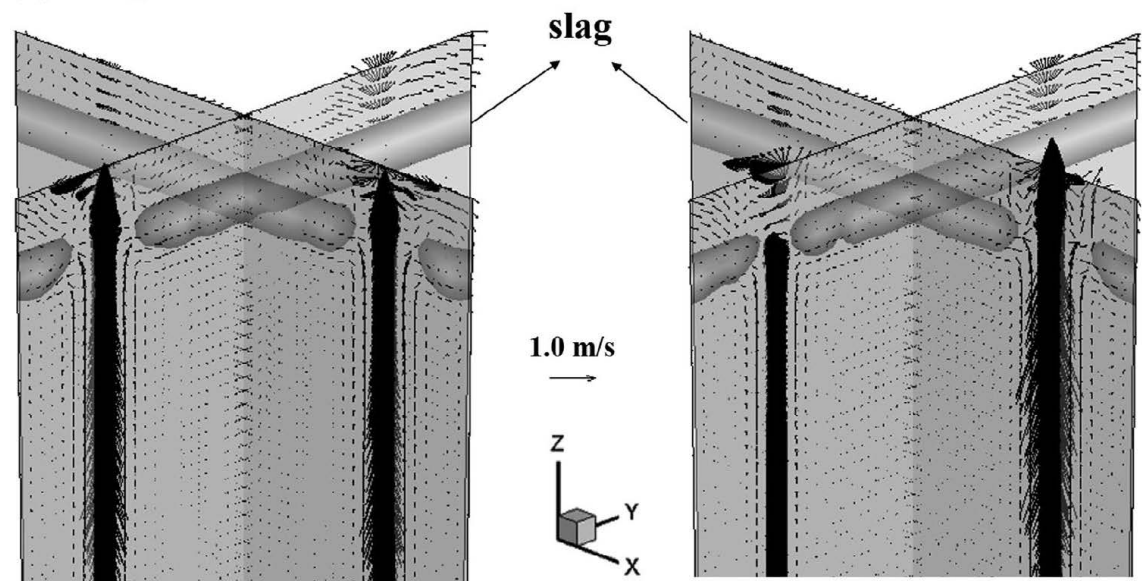

Fig. 13. Comparison of velocity vectors between using Mode-S (a) and Mode-D (b). (a) $400+400 \mathrm{NL} / \mathrm{min}$

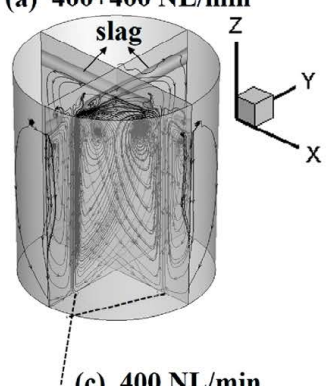

(c) $400 \mathrm{NL} / \mathrm{min}$

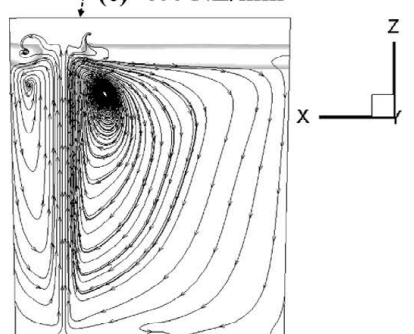

(d) $100 \mathrm{NL} / \mathrm{min}$

(b) $100+700 \mathrm{NL} / \mathrm{min}$

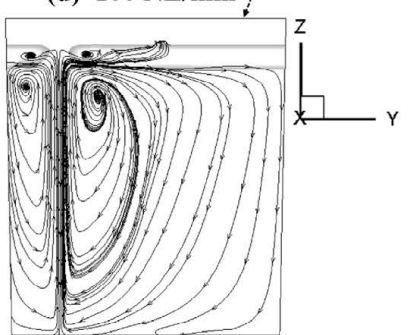

$700 \mathrm{NL} / \mathrm{min}$

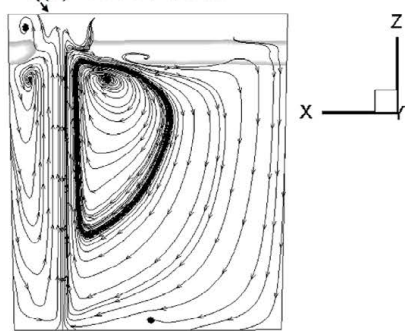

Fig. 14. Comparison of velocity streamlines between using Mode-S (a, c) and Mode-D (b, d, e) at the main section.

(a)

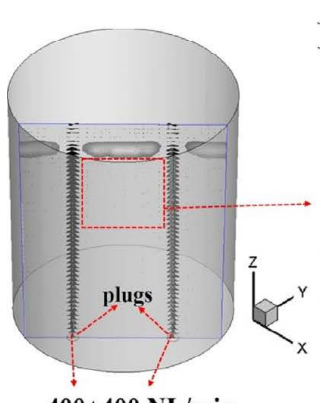

$400+400 \mathrm{NL} / \mathrm{min}$ (b) $\stackrel{0.3 \mathrm{~m} / \mathrm{s}}{\longrightarrow}$

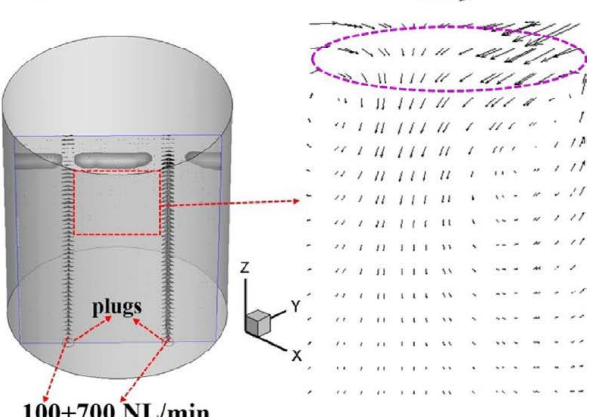

Fig. 15. Comparison of velocity vectors between using Mode-S (a) and Mode-D (b) at the vertical plane passing through the two plugs. (Online version in color.)

and cluster in the middle and top regions of the ladle, which will dissipate some gas stirring energies. The researches of Iguchi ${ }^{18)}$ and $\mathrm{Zhu}^{26}$ show that the mixing time is negative correlated to the stirring energy, thus the mixing time for this mode is prolonged. In Figs. 14(b), 14(d), 14(e), the formed flow field by two plumes is asymmetric and the vortex cores of two plugs are not at the same height due to the difference of gas flowrates between plugs, which will significantly impair the collision and dissipation between streams, further make the stirring energy utilized more fully.

The velocity vectors of Mode-S and Mode-D in a tiny region of the vertical plane passing through two plugs are shown in Fig. 15. As seen, the distribution of flow field along the vertical central line is symmetric for Mode-S (Fig. 15(a)), and the eddy height and size is almost the same. However, for Mode-D (Fig. 15(b)), the strong plume forms a larger circulation flow to stir the ladle and the weak plume forms a smaller one. Under this case, the interference and 
collision from plumes is relatively weaker than Mode-S at the same total flowrate.

To verify the simulation result in Fig. 15, the ink experiment was performed to show the flow field of the vertical plane passing through two plugs. $60 \mathrm{~mL}$ of ink for every nozzle was added from the location of gas blown at the same speed, and the result is shown in Fig. 16. It is seen that the flow field is significantly different for the two modes. Two plumes of Mode-S (Fig. 16(a)) is almost symmetric, and they also form symmetric back flows at the liquid level. These back flows collide each other as marked in the figure. While for Mode-D (Fig. 16(b)), the strong plume first reaches the liquid level, and then extends to the weak plume side, thus the collision between the top plumes will be greatly impaired. The results are in good agreement with Fig. 15.

To further compare the stirring effect of two modes, the velocities of five cross sections (300, 500, 700, 1000,1500 $\mathrm{mm}$, as shown in Fig. 17) of the ladle along Z-direction in velocity vectors were analyzed, and relatively inactive zone proportions (relatively inactive zone is defined as the zone whose flow velocity is less than $0.01 \mathrm{~m} / \mathrm{s}$ ) at $5 \mathrm{~s}$ upon gas blowing were counted by Tecplot 360 and Photoshop softwares. The results are shown in Fig. 18.

It is seen that the nearer the cross section is to the ladle bottom, the larger the inactive zone proportion is. It reaches $80 \%$ and $60 \%$ respectively at the cross section of $300 \mathrm{~mm}$, decreasing to $25 \%$ and $8 \%$ at $1500 \mathrm{~mm}$. In addition, the inactive zone proportions of Mode-D are significantly lower than Mode-S, which in return indicating Mode-D is beneficial to the mixing of molten steel. The result also explains why it has shorter mixing time in water model experiment.

\subsection{Correlation for Mixing Time}

The researches above indicate that, for the multi-plug ladle, the relationship of mixing time and the factors such as plug positions, angles, gas flowrates and blowing mode is complex, which cannot be simply deduced only by theory.

The fitted correlation for mixing time by experimental data is obtained as follows:

$$
\begin{aligned}
& \tau_{\mathrm{m}}= \\
& 158.80(\theta)^{0.01258}\left(\frac{r}{R}\right)^{0.01525}\left(Q_{\mathrm{T}}\right)^{-0.25866}\left(f_{\mathrm{w}}\right)^{0.21432}\left(f_{\mathrm{s}}\right)^{-0.47298}
\end{aligned}
$$
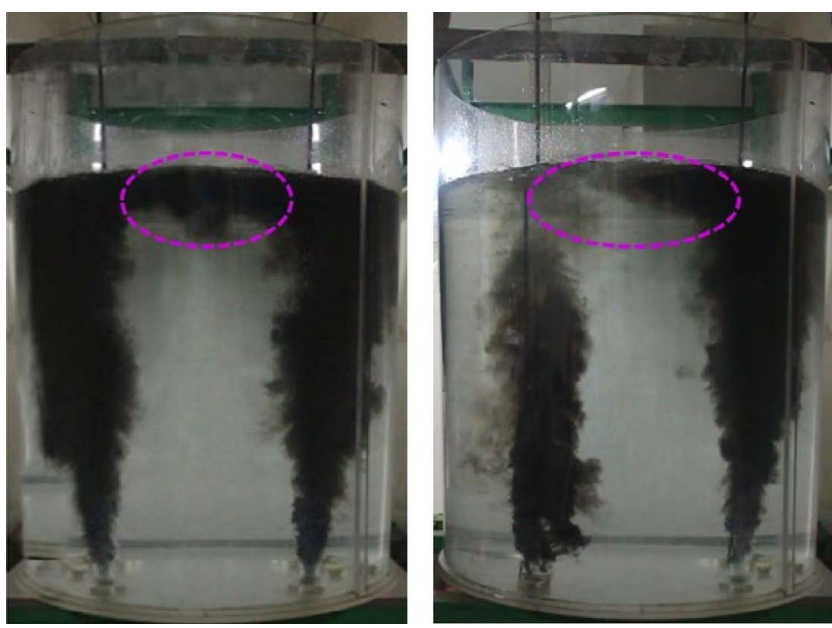

Fig. 16. Verification for Fig. 15 with ink. (Online version in color.) where $\theta$ represents the angle between plugs, $\operatorname{rad} ; \frac{r}{R}$ is the dimensionless plug position; $Q_{\mathrm{T}}$ is the gas total flowrate, $\mathrm{NL} / \mathrm{min} . f_{\mathrm{w}}$ and $f_{\mathrm{s}}$ are the fractions of the gas flowrates of the weak and strong plumes in the total flowrate, respectively, which can be expressed as $f_{\mathrm{w}}=\frac{Q_{\mathrm{w}}}{Q_{\mathrm{T}}}$ and $f_{\mathrm{s}}=\frac{Q_{\mathrm{s}}}{Q_{\mathrm{T}}}\left(Q_{\mathrm{w}}\right.$ presents the gas flowrate of weak plume; $Q_{\mathrm{s}}$ is the gas flowrate of strong plume).

The exponent for $Q_{\mathrm{T}}$ is -0.25866 , indicating that the mixing time decreases with increasing total gas flowrate. The exponents of $f_{\mathrm{w}}$ and $f_{\mathrm{s}}$ is 0.21432 and -0.47298 , respectively, indicating the strong plume has a larger influence on mixing time. The exponents of $\theta$ and $\frac{r}{R}$ are 0.01258 and 0.01525 , respectively, which are smaller than that of gas flowrate, suggesting their influence weaker than gas flowrate.

For Mode-S, $f_{\mathrm{w}}=f_{\mathrm{s}}=0.5$, thus Eq. (15) is transformed into Eq. (16):

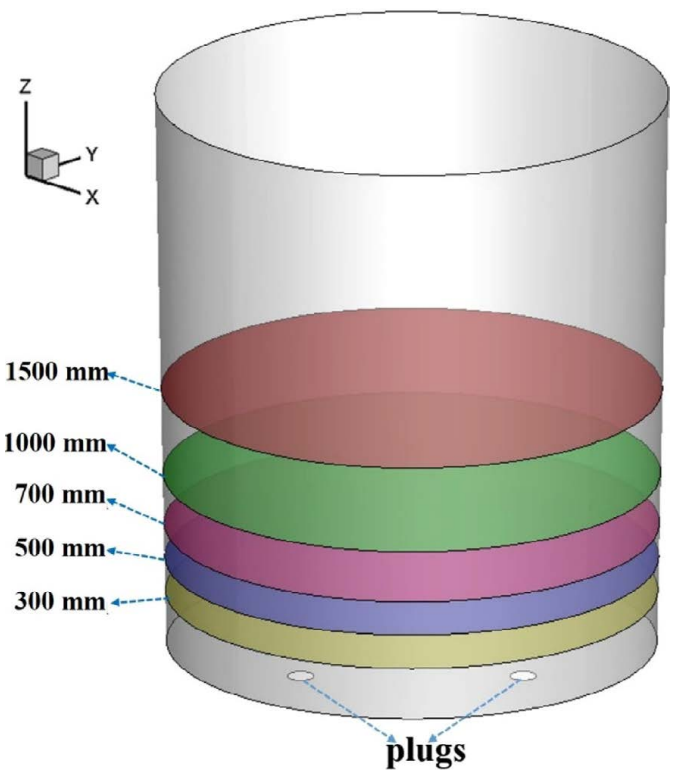

Fig. 17. Schematics of five cross sections of ladle. (Online version in color.)

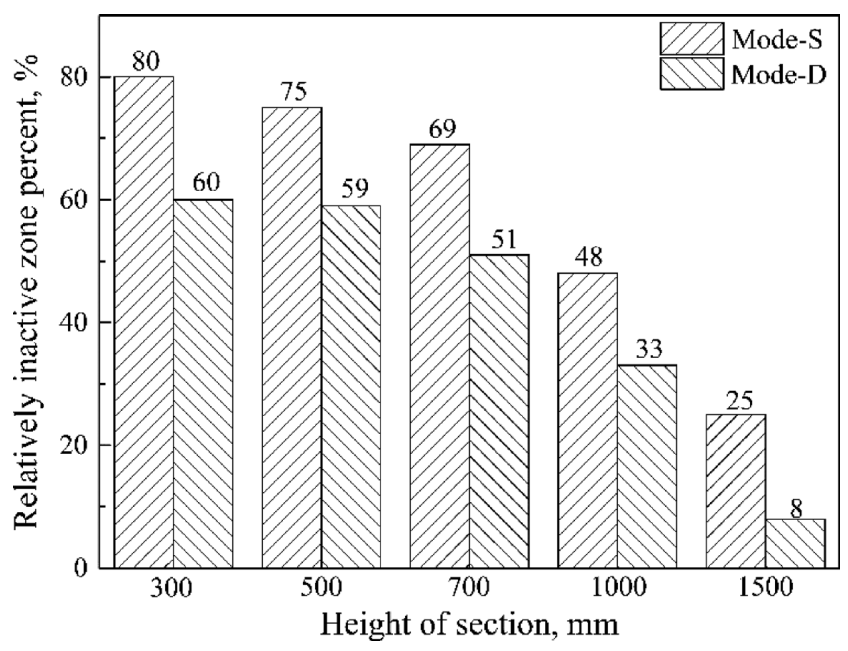

Fig. 18. Comparison of relatively inactive zone percent for five cross sections at $5 \mathrm{~s}$ upon gas blowing. 


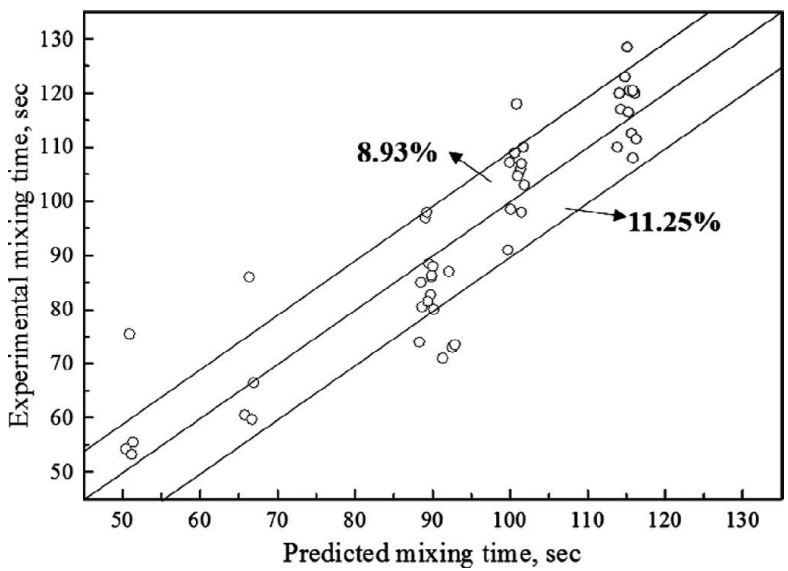

Fig. 19. Relationship between experimental and predicted results on mixing times.

$$
\tau_{\mathrm{m}}=189.98(\theta)^{0.01258}\left(\frac{r}{R}\right)^{0.01525}\left(Q_{\mathrm{T}}\right)^{-0.25866}
$$

The comparison of experimental data and predicted values for the current experimental work is in Fig. 19. For the most points, the differences between the calculated and actual values are within $-8.93 \%$ and $+11.25 \%$.

\section{Conclusions}

A water model study of $120 \mathrm{t}$ ladle has been performed to mainly discuss the effect of gas blowing modes on mixing. Two plugs used in these experiments are located at $0.55-0.70 \mathrm{R}$, with different relative angles $\left(45-180^{\circ}\right)$ and gas total flowrates (6.92 to $18.45 \mathrm{NL} / \mathrm{min})$. Based on the current study, the following conclusions can be drawn:

(1) The gas blowing mode influences the mixing of the ladle. For the present study, the mode with different flowrates for dual plugs can significantly decrease the mixing time compared with the same flowrates. Under the stirring conditions of gas total flowrate $6.92 \mathrm{NL} / \mathrm{min}$ and $18.45 \mathrm{NL} /$ min, the mixing time is respectively decreased by about $42 \%$ and $35 \%$ at most, compared with the prototype.

(2) The mixing time has a complicated relationship with the plug positions and relative angles. For Mode-S, the mixing time generally increases when the relative angle changes from $45^{\circ}$ to $90^{\circ}$. However, the change rate becomes small with the plugs is far away the ladle center. When the relative angle varies from $90^{\circ}$ to $180^{\circ}$, the mixing time decreases due to the decrease in the stirring energy consumed by the collision and interaction from two plumes.

(3) For Mode-S, the case $0.55 \mathrm{R}$ and $45^{\circ}$ can obtain the shortest mixing time, but the slag eye of the ladle is enlarged. The mixing time of cases $0.7 \mathrm{R}+180^{\circ}, 0.64 \mathrm{R}+135^{\circ}$ and $0.55 \mathrm{R}+180^{\circ}$ is all shorter than the prototype, which can be suggested in industrial use.

(4) The results of mathematical simulation explain that of water modeling. The velocity vectors and streamlines of different blowing modes as well as the comparison of the inactive zone proportions show that the difference of mixing time is from the flow styles and the stirring energy dissipation.

(5) A correction for mixing time in this ladle is expressed as $\tau_{\mathrm{m}}=158.80(\theta)^{0.01258}\left(\frac{r}{R}\right)^{0.01525}\left(Q_{\mathrm{T}}\right)^{-0.25866}\left(f_{\mathrm{w}}\right)^{0.21432}\left(f_{\mathrm{s}}\right)^{-0.47298}$.

\section{Acknowledgments}

The authors are grateful for the support of the National Natural Science Foundation of China (No. 51374021) and the Fundamental Research Funds for the Central Universities of China (No. FRF-UM-15-048).

\section{REFERENCES}

1) H. Y. Tang, J. S. Li, C. H. Xie, S. F. Yang, K. M. Sun and D. S. Wen: Int. J. Min. Met. Mater., 16 (2009), 383.

2) J. Mandal, S. Patil, M. Madan and D. Mazumdar: Metall. Mater. Trans. B, 36B (2005), 479.

3) D. Mazumdar and J. W. Evans: Metall. Mater. Trans. B, 35B (2004), 400 .

4) K. Krishnapisharody and G. A. Irons: Metall. Mater. Trans. B, 37B (2006), 763.

5) U. Singh, R. Anapagaddi, S. Mangal, K. A. Padmanabhan and A. K. Singh: Metall. Mater. Trans. B, 47B (2016), 1.

6) D. Q. Geng, H. Lei and J. C. He: Int. J. Min. Met. Mater., 17 (2010), 709.

7) C. G. Mendez, N. Nigro and A. Cardona: J. Mater. Process. Technol., 160 (2005), 296.

8) H. Liu, Z. Qi and M. Xu: Steel Res. Int., 82 (2011), 440.

9) Y. S. Chen, Y. J. Pang and X. G. Zhang: Adv. Mater. Res., 146 (2011), 1031.

10) K. Nakanishi, J. Szekely, T. Fujii, Y. Mihara and S. Iwaoka: Metall. Trans. B, 6B (1975), 111.

11) K. Mori, M. Sano and T. Sato: Trans. Iron Steel Inst. Jpn., 19 (1979), 553.

12) Y. Sahai and R. I. L. Guthrie: Metall. Trans. B, 13B (1982), 125.

13) Y. Sahai and R. I. L. Guthrie: Metall. Trans. B, 13B (1982), 193.

14) A. M. Amarovilleda, M. A. Ramirezargaez and A. N. Conejo: ISIJ Int., 54 (2014), 1.

15) D. Mazumdar, H. Nakajima and R. I. L. Guthrie: Metall. Trans. B, 19B (1988), 507

16) Y. Kishimoto, Y. Sheng, G. A. Irons and J. S. Chang: ISIJ Int., 39 (1999), 113.

17) D. Mazumdar and R. I. L. Guthrie: Metall. Mater. Trans. B, 41B (2010), 976.

18) M. Iguchi, K. I. Nakamura and R. Tsujino: Metall. Mater. Trans. B, 29B (1998), 569

19) J. W. Han, S. H. Heo, D. H. Kam, B. D. You, J. J. Pak and H. S. Song: ISIJ Int., 41 (2001), 1165.

20) K. Nakanishi, T. Fujii and J. Szekely: Ironmaking Steelmaking, 3 (1975), 190 .

21) K. Nakanishi, K. Saito. T. Nozaki, Y. Kato, K. Suzuki and T. Emi: Steelmaking Conf. Proc., 65 (1982), 101.

22) M. Sano and K. Mori: Trans. Iron Steel Inst. Jpn., 23 (1983), 169.

$23)$ S. Asai, T. Okamoto, J. C. He and I. Muchi: Trans. Iron Steel Inst. Jpn., 23 (1983), 43.

24) D. Mazumdar and R. I. L. Guthrie: Metall. Trans. B, 17B (1986), 725.

25) H. Turkoglu and B. Farouk: ISIJ Int., 31 (1991), 1371.

26) M. Y. Zhu, T. Inomoto, I. Sawada and T. Hsiao: ISIJ Int., 35 (1995), 472.

27) G. G. K. Murthy, S. P. Mehrotra and A. Ghosh: Metall. Trans. B, 19B (1988), 839.

28) G. G. K. Murthy and J. F. Elliott: ISIJ Int., 32 (1992), 190.

29) M. Chen, N. Wang, Y. Yao, J. Geng and K. Xiong: Steel Res. Int., 78 (2007), 468.

30) M. S. C. Terrazas and A. N. Conejo: Metall. Mater. Trans. B, 46B (2015), 711.

31) B. Li, H. Yin, C. Q. Zhou and F. Tsukihashi: ISIJ Int., 48 (2008), 1704 .

32) C. A. Llanos, S. Garcia-Hernandez, J. A. Ramos-Banderas, J. de Barreto and G. Solorio-Diaz: ISIJ Int., 50 (2010), 396.

33) S. W. P. Cloete, J. J. Eksteen and S. M. Bradshaw: Miner. Eng., 46 (2013), 16.

34) S. W. P. Cloete, J. J. Eksteen and S. M. Bradshaw: Prog. Comput. Fluid Dyn. Int. J., 9 (2009), 345.

35) Fluent: ANSYS Academic Research, Release 14.5, Fluent, Pittsburgh, (2012). 